\title{
The Status Quo Investigation and Study of Mathematics accomplishment of Five-year Normal College Rural Oriented Students in Jiangxi Province
}

\author{
Qiu-hua Zhou ${ }^{1, a}$, Fei Sun ${ }^{2, b}$ \\ ${ }^{1,2}$ Nanchang Normal College, Nanchang ,JiangXi,330103, China \\ a648838085@qq.com, ${ }^{\mathrm{b}} 13361620499 @ q q . c o m$
}

Keywords: Five-year, Rural directional normal college students, maths.

\begin{abstract}
Five-year Normal College Rural Oriented Students in Jiangxi Province is to enhance the level of rural primary school teachers in jiangxi province and set up a new system of teachers. Through this study it is aimed to discover the problems in the orientation training, as well as the factors hindering the research on the directional students mathematics attainmen.Based on the analysis of the causes, put forward to improve five-year construct rural directional students mathematical literacy measures, so as to cultivate a good rural primary school maths teachers group, to narrow the gap between urban and rural elementary school mathematics teaching,and promote the balanced development of the urban and rural education.
\end{abstract}

\section{First, the research background}

Five-year normal college rural oriented students in Jiangxi Province, beginning from 2007, is a new system of teachers set up to promote rural primary school teachers.It is " $3+2$ " cultivation mode from the junior high school as a starting point, which Ss study foundation course in the former 3 years and learn college curriculum of elementary education in the latter two years.According to the effects of admissions requirements, the preference of rural directional students ensures the quality of five-year normal college rural oriented students in Jiangxi Province graduating from Junior schools. Directional students generally get high test scores, according to preliminary investigation, who choose to redirect to rural primary school as a teacher, which isn't their real ideal, for their family economic pressure, and a stable job. The incentive they make life ideal and the lack of learning motivation and no worries about employment, let them have superiority and pride and then so being directional normal college students results in a confusing period. Pressure loss, the ideal disillusionment, pride from being compared with their peers or inferiority complex are plagued by these intelligent and sensitive Ss.So they lack the initiative to improve the quality in mathematics. Mathematics abstract and logical characteristics decide mathematics teaching is a difficulty in the primary school teaching work.Thus to improve these directional students' mathematics attainment, mastering mathematics teaching basic knowledge basic skills, basic method engaged in an elementary school is the key to develop.The study is to lay a solid foundation for developing rural good elementary school mathematics teachers based on the five-year rural directional students maths attainments.

\section{Second, the research purpose}

Through the investigation, the problems existing in the orientation training is to be discovered , as well as the factors hindering the research on the directional maths students improving. On the basis of the revision of the original training scheme, put forward to effective measures to this kind of students, cultivate a maths good rural primary school teacher team, so as to improve the quality of rural elementary school mathematics teaching, to narrow the gap between urban and rural elementary school mathematics teaching and promote the balanced development of the urban and rural primary school education. 


\section{Three, the research hypothesis}

Before the investigation, this study made the following assumptions:

1. These students after enrolled are hard to meet the needs of teachers of mathematics learning, and there is a gap from the non-rural students, thus to carry out the investigation about the maths present situation.

2. There is a close relation between their education background and their adapting learning after being enrolled.This study will investigate by combining the degree of mathematics learning and the education background.

3. Five years construct rural directional students' maths problem can be promoted through normal education by setting adaptive directional project of cultivating students' intervention. Rural teachers literacy will be improved greatly. On this assumption, the intervention strategy is made.

4. Five years construct rural directed the cultivation of the students' maths problem is a very complicated engineering education system. Therefore, attention should be paid to the adjustment of strategy, to adapt to the needs of the elementary school mathematics teachers' work.

\section{Four, the research object and methods}

(a) the research object: in order to objectively understand the directional students mathematics accomplishment present situation,the study sets the five years construct rural directional students as the research object, and does directional normal random sampling survey by using the self-made questionnaire for each gender and grade.The survey questionnaires got 467 ones out of 480, recycling,recovery rate 97.29\%.In recycling questionnaires, there are 452 valid ones. While editing the interview outline, and interviewing directional class students, the teacher in charge, as part of the rural teacher, the status have finally been obtained, i.e.the status quo of the rural directional students mathematical literacy, and factors hindering the research on the rural directional improve students mathematics attainment.

(b) research methods: this study is carried on under the environment of normal education teaching work, the specific methods are:

1. Literature study method: through the rich collection and network academic resources, related literature for improving five-year construct rural directional students' mathematics is to be combed and explored, vulnerabilities are to be found and the latest research progress is to be mastered.

2. The investigation and interview method: based on the five-year construct rural directional students mathematics study is to be surveyed on field trips and at the same time the education teaching-work related teachers and teachers engaged in the work of rural directional students mathematics teaching are to be interviewed, questionnaires granted. On this basis, it is to be explored to improve five years effective way to construct rural directional students mathematical literacy.

3. comparative research: it is to be explored what is the difference between five-year-system rural directional students' maths with the non-directional ones and what is mathematics learning strategies for five-year-system rural directional students by comparing.

4. The case study method:select some typical in five-year-system rural directional students to analyze in detail for their learning attitudes and habits and eventually conclude the effective measures to improve maths.

The study follows the methods from practice to theory and practice. What specific method is adopted will be combined with the actual situation.

\section{Five, the data analysis}

1. The entrance will is strong but there is a deviation for the incentive and professional knowledge is not high

Questionnaire survey indicates that among the students who choose a directional normal college,girls account for $72.31 \%$. Directional students are, almost from the countryside, have many brothers and sisters, among whom are only children rarely.42.22\% students choose directional 
normal because in the future they will have a steady job, $34.44 \%$ because of the requirement of the family or the original school teachers' advice, $9.13 \%$ because of family economic difficulties, hoping to reduce the family economic burden. The purpose of five-year-system rural students' orientation is to get a steady job, looking to their own interests above all else. The incentive is not for the love of primary school teachers' work.The concept of "ethics first" is not set up so that they will not consider the country needs and don't realize what they shoulder the important task of the education of the next generation.

2. The learning purpose is clear but they lack learning initiative and interest in learning is not strong

When asked about the purpose of learning mathematics, questionnaire survey shows that $53.5 \%$ of the students think learning math is to master the basic mathematics knowledge, up to the needs of the elementary school mathematics, $23.9 \%$ of them that learning math is to know the law of mathematics teaching and improve the maths, $22.5 \%$ that learning math is to pass the exam and to get the course credits.Most of the five-year-system rural directional students have clear mathematics study purpose. $54.9 \%$ of the students think while before enrolled they have good mathematical foundation but mathematics learning is boring, especially higher mathematics is difficult, which results in weak study interest.Only $16.9 \%$ of the students think they learn math talent is good, very interested in mathematics. Learned in the interviews, some classmates in mathematics learning, especially lack learning initiative for higher mathematics and have the fear without confidence which results from the following: elementary mathematics is simple to understand, through intensive training, easy to achieve the ideal result. after they become students of five-year-system,mathematics study time is short, content abstract, especially courses such as the mathematical analysis, higher algebra and space geometry theory are abstract,whose computation task is heavy.Some concluding also needs to pass strict reasoning and needs to have the abstract thinking and rich spatial imagination ability. Some students,still in accordance with the mechanical memory of junior high school learning method, can not adapt to the change of mathematics learning. Five-year-system rural directional students can't get rid of the plight of junior middle school learning leader.When they learn their classmates are enrolled into the key high school and admitted to key universities but their own future is to be rural teachers, it was hard to avoid disappointment.The contradiction between the ideal and the reality makes them lack of initiative in study.

3. The mathematical foundation is good, but they are short of scientific learning method and communication awareness is not strong

Good study habits include learning self-confidence, active preparation before class, very attentive listening and bold questioning in class, after-school review and independent finishing of the homework in time. It was found in the survey that students having the preparation habit accounted for 23.4\%,insisting to do class notes(43.7\%), exploring mathematical problems and boldly questioning in class only $9.2 \%$, reviewing only $4.2 \%$, independently finishing the homework on time (26.8\%) and often reviewing the mathematics knowledge $12.7 \%$. From the results of the survey, five-year-system rural directional students, although their foundation is good before entering school mathematics foundation is good, they lack scientific learning methods and the good study habits.The majority of students' learning self-confidence is poor, can't actively learn, passively have tests and mechanical memory phenomenon is more serious.Interactive teaching is commonly used in the process of mathematics teaching mode.Classroom communication is an important part of the teachers and students to complete the teaching mission. According to the survey, in the process of teaching, the students actively involved in the problems to explore account for $73.2 \%$ and $11.3 \%$ of the students in the classroom boldly published their ideas. $54.3 \%$ of the students can listen to the views of the classmate, but they don't want to communicate with classmates and $4.2 \%$ of the students don't participate in class discussion, basicly reading or doing other things. This shows that directional students from the countryside were not involved mathematics exchanges confidently. Such a classroom teaching is difficult to give full play to students' subjective initiative, influencing the improvement of students' mathematics accomplishment. 
4. The teaching ideas are advanced but it lacks proper teaching materials and learning result is bad

With the advancing of the new course standard, normal colleges and universities are to adapted themselves to the requirement of new teaching concept.However, the teaching material of five-year-system rural directional students are outdated, five-year-system rural directional students for basic math having an original normal school and high school mathematics teaching material, in the tertiary period mathematics in higher vocational or undergraduate course teaching material. The survey shows: $79.8 \%$ of the students don't agree with, or accept current mathematics textbooks.Students generally believe that the original normal school mathematics teaching material contents are too old, the high school mathematics teaching material requirement too high, tertiary period of higher mathematics teaching material for them in the elementary school mathematics teaching not effective. The main reason is that the integrity of the traditional mathematical content focuses on discipline system itself, is not conducive to the cultivation of students' mathematics accomplishment, teaching pertinence not strong, and primary school mathematics curriculum content disconnected and didn't find five-year-system rural directional students writing teaching material so that it leads to directional students cannot very well grasp the elementary school mathematics teaching content during the learning process and can not explore cognitive characteristics suitable for primary school mathematics.In a word, the teaching effect is not good.

5. Training goal is clear, but it lacks the corresponding training plan and students are short of comprehensive qualities

The mathematics education training goal of five-year-system rural directional students is: to cultivate application-based specialized personnel in the work with specialized degree, all around development of moral intellectual physical aesthetics and labour education and sound personality, who are able to adapt to China's political, economic, cultural and social development needs, be expertise in learning, have a certain ability to innovate and teaching research ability and be qualified for the compulsory education stage mathematics discipline and one or two other subjects in teaching and education. Specific requirements: love primary school education career, have good professional ethics and code of conduct, to master the basic theory ,basic knowledge and basic skills of this major, understand mathematical thought and methods, learn to analyze and solve problems from the perspective of mathematics,enhance the students' practical ability, improve the maths and have certain knowledge of humanities and social science and natural science knowledge.In the interview, it was found that although five-year rural directional learning system had been implemented for many years, no training scheme for directional normal students wasn't made.In most of the schools non-training scheme for directional normal students is being carried on.Individual schools have their separate training schemes, but that doesn't reflect the characteristics of directional students obviously, in which there are only the differences between simple cuts and teaching schedules and doesn't show "tailored" five-year-system rural directional students' mathematics accomplishment promotion strategy.

\section{Six, the conclusion and the suggestion}

1. From the perspective of teacher's teaching, make a mathematics teaching reform

Teachers,always playing a dominant role in cultivating five-year-system rural directional students, ,are the key to develop elementary school mathematics teachers with a strong professional ability. A teacher should study seriously five-year-system rural directional students' family background, education background, and characteristics of students' learning basis, give full consideration to their training target and the needs of the future elementary school mathematics teaching, according to the current training scheme and teaching materials and actively devote themselves in the education teaching reform of five-year-system rural directional students to make the teaching method to benefit students' mathematical literacy development. In the choice of teaching methods, a variety of mental factors and the potential of non-intelligence play out at the same time.By using flexible teaching methods such as taking the question guide mode through the classroom 
communication, inspire the student to carry out the thinking of a problem, to explore the solution to the problem and stimulate students' interest in learning mathematics and their inspiration of mathematics thinking to generate strong desire of knowledge for mathematics study, which can change passive to active learning and dull mathematics into lively and culticvate the good quality of students' positive thinking.

2. From the perspective of students learning, strengthen the mathematics research method instruction

Strengthen professional ideological education and train the students' self-confidence to study mathematics . If students have strong interest in mathematics, they will actively participate in the math problem to explore and on the contrary, if having no interest in math, they will feel mathematics dull and learning math a painful torment. To culture mathematics study interest of students for five years, first by professional education thought, change ideas to help them build up confidence and through the story interesting mathematics and modern teaching tools, eliminate prejudice of mathematics;Second, the guidance in learning methods helps them find an effective method not only suitable for the practice of students' learning and obeys the law of mathematics learning .Improve the learning efficiency cultivate the habit of good study mathematics by guiding students to establish reasonable plans and solve questions through guiding preparation before class and class lesson digestion; Finally, mathematical covers mathematical thinking methods, among which the four are commonly used i.e. function and equation, categorical discussion ideas and equivalent conversion of ideas and the three main methods are the changing element method, the completing square method and the method of undetermined coefficients.In the process of teaching, seepage mathematics thinking method to students and improve their maths by using these methods to understand elementary school mathematics content under a well versed curriculum.

3.from the perspective of compiling textbooks, strengthen mathematical literacy cultivation

Five-year-system rural directional normal students use obsolete content of teaching materials that disconnect primary school teaching contents,so that the design of teaching materials should be paid attention to the unity of the primary school teaching content and the cultivation of students' mathematics accomplishment must be strengthened. It is recommended that following fully survey of the present situation of five-year-system rural directional students, according to the concept of the new teaching standard, on the basis of the elementary school mathematics "number and algebra, graphics and geometry, statistics and probability, synthesis and application of" four major areas, inserting the elementary school mathematics in the corresponding teaching materials while writing teaching material that should contact the elementary school mathematics content five years should be important part of training five-year-system rural directional students' mathematical education. Let the students grasp compulsory mathematics teaching theory knowledge in the elementary school while learning mathematics, through practice teaching for students to grasp the guiding role of higher mathematics in the elementary school mathematics content,and stand at a high Angle of view to understand the elementary school mathematics related content by using the relevant theories of higher mathematics knowledge. In this mode, it is helpful to stimulate students' interest in learning, cultivate good character of mathematics and strengthen mathematical literacy cultivation.

4. From the Angle of training scheme, emphasizing mathematical literacy

Whether the professional training scheme for five-year-system rural students is scientific or not is one of the keys in normal colleges to train and develop qualified elementary school mathematics teacher.Good or bad performs on their professional ability. Adjusting the proportion theory class and practice class and strengthening practice teaching is imperative. Only emphasizing on theoretical courses in the curriculum system results in students' solid mathematical theory but poor practice ability,which can't escape out of the shadows exam-oriented education. The traditional exam-oriented education is easy to dispel students' enthusiasm to study mathematics. According to current situation of heavy theory but light practice, maths must be paid attention to, the professional training scheme for five-year system rural students present to revise and formulate suitable for their professional development training scheme. One is to emphasize the normal characteristics. When making construct directional normal training scheme for five years, the needs of the students in primary school teaching in the future should be given full consideration to.In the protection of the main 
professional course, open comprehensive practice activities and guidance, multimedia computer assisted instruction, history of mathematics, college students' mental health education, and class management work with the young pioneers, such as increasing the training practice course class. The second is to strengthen the practice ability training. According to the Ministry of Education to strengthen students' professional basic skills and training requirements, strengthen education trainee internship guide, for the students with the chance to view teacher lectures, increase the intensity of training, let the student to apply professional knowledge to the classroom teaching practice, found the problem in practice, accumulate experience, and in practice to review the mathematical accomplishment and ability of students.

\section{References}

[1] Zhi-hua Tang. Five-year-system normal mathematics curriculum research [D]. Jiangsu, Nanjing normal university, 2004.

[2] Wang Yu. Five-year-system higher vocational talents training practice and exploration, in Wuzhou vocational college, for example [J]. Journal of vocational education (under the ten-day), $2014(2)$.

[3] Jian-guo Huang.Five-year-system construction class specialized practice teaching study [J]. Journal of Hubei radio and TV university, 2011 (12).

[4] Mr Li. Requirements for the quality of the students in normal colleges in the new period [J]. Journal of Shanxi normal university to continue education, 2004 (01).

[5] Zhu Zhenyue. Zhejiang to promote "five-year-system vocational education pilot project" [N]. China education news, 2013-4-5 (1).

[6] Guo Yuxiang xiu-li xian. How to cultivate students new ways of issues and their change strategies [J]. Journal of higher education BBS, 2013 (6).

\section{This fund project:}

2014 Jiangxi education scientific planning project (project number 14 yb141) one of the research results 